\title{
Precursory Indicator for Mode I Fracture in Brittle Rock through Critical Slowing Down Analysis
}

\author{
Zhenghu Zhang $\mathbb{D},{ }^{1,2}$ Tao Chen $\mathbb{D},{ }^{3}$ Ke Ma $\mathbb{D},{ }^{1}$ Tiexin Liu $\mathbb{D}^{4},{ }^{4}$ and Jianhui Deng $\mathbb{D}^{2}$ \\ ${ }^{1}$ School of Civil Engineering, Dalian University of Technology, Dalian 116024, China \\ ${ }^{2}$ State Key Laboratory of Hydraulics and Mountain River Engineering, Sichuan University, Chengdu 610065, China \\ ${ }^{3}$ Bureau of Housing and Urban-Rural Development of Dongxihu District, Wuhan 430030, China \\ ${ }^{4}$ Department of Civil Engineering, Dalian Maritime University, Dalian 116026, China \\ Correspondence should be addressed to Ke Ma; mark1983@dlut.edu.cn
}

Received 16 April 2020; Revised 28 October 2020; Accepted 19 November 2020; Published 1 December 2020

Academic Editor: Hongwei Yang

Copyright ( $) 2020$ Zhenghu Zhang et al. This is an open access article distributed under the Creative Commons Attribution License, which permits unrestricted use, distribution, and reproduction in any medium, provided the original work is properly cited.

\begin{abstract}
The abrupt rock-related hazards, such as landslide, rock burst, and collapse, seriously threaten the safety and service life of engineering works. Precursory information on critical transitions preceding sudden fracture is of great significance in rock mechanics and engineering. This study investigates the critical slowing down feature of acoustic emission (AE) signals and precursory indicators during the mode I fracture process of brittle rock. Cracked chevron notched Brazilian disc (CCNBD) specimens were utilized, accompanied by acoustic emission monitoring. The principle of critical slowing down was introduced to study AE count sequences, and the variance and autocorrelation coefficient versus loading time curves were analyzed. The results show critical slowing down phenomenon exists during mode I rock fracture. The variance and autocorrelation coefficient of AE counts grow significantly prior to rock fracture, and thus, the significant growth of variance and autocorrelation coefficient of $\mathrm{AE}$ signals can act as the precursory indicator of rock fracture. Compared to the autocorrelation coefficient, the precursors determined by the variance are more remarkable. The time interval between the precursory indicator using the critical slowing down theory and fracture moment ranges from $2 \%$ to $15 \%$ of the entire loading time. The findings in this study could facilitate better understandings on the rock fracture process and early-warning technique for rock fracture-related geological disasters.
\end{abstract}

\section{Introduction}

The stability of rock structures is important in extensive engineering fields, such as coal mining, tunnel excavation, water resources, and hydropower engineering. By contrast, rock failure and instability during the engineering construction and performance periods may cause a series of geological disasters, including landslide, rock burst, collapse, and large deformation of the tunnel, which seriously threatens the safety and service life of engineering works. Therefore, it is of great significance to study the precursory information and early-warning technology of rock fracture.

A rock inevitably contains preexisting defects, e.g., microcracks, cavities, and pores. When the rock is subjected to external forces, the stress concentrations are generated around preexisting defects and the rapid release process of localized strain energy is accompanied by acoustic emission (AE) phenomena [1-3]. Since German scientist Kaiser [4] verified the acoustic emission phenomenon of common engineering materials, the $\mathrm{AE}$ technique has been widely used in rock mechanics and engineering [5-7]. Many scholars investigated the characteristics and precursory information of AE signals during the rock deformation and damage process, e.g., the remarkable increase in the number and release rate of $\mathrm{AE}$ counts or events $[8,9]$, the change of seismic $b$-value [10-12], the variation of spatial correlation length $[13,14]$, frequency spectrum characteristics $[15,16]$, and fractal characteristics [17-21].

The critical slowing down phenomenon exists in a complicated dynamical system as the system shifts suddenly 
from one stable state to another contrasting one, which has attracted widespread attention in many fields [22-25]. Dakos et al. [22] and $\mathrm{Wu}$ et al. [26] assumed that slowing down could be viewed as a precursor for upcoming catastrophic climate change. The literature [27-29] investigated the critical slowing down phenomenon preceding a bifurcation from a stable equilibrium to a chaotic state in the ecosystem. Yan et al. [30] stated that the critical slowing down characteristics are a possible early sign for upcoming earthquakes. Ren and Watts [31] showed statistical measures occur in the energy supply infrastructure upon reaching abrupt large-scale disruptions in the electrical system. Obviously, the critical slowing down theory provides a new sight to identify whether a dynamical system is undergoing a critical transition.

Although the critical transition feature has been widely studied in extensive fields [23, 25], spanning from the ecosystem to the climate and seismic systems, the critical slowing down characteristics of AE signals preceding rock failure are in their infancy. Kong et al. [32] and Wei et al. [33] analyzed the early signs of AE counts in coal and sandstone during uniaxial compression tests. Zhang et al. [34] investigated the critical slowing down characteristics of electric potential (EP) generated during the sandstone failure process subjected to compression. However, the critical slowing down feature of AE signals during the rock damage process under other types of loading, especially mode I fracture, is still absent.

The purpose of this paper is to study the critical slowing down feature of acoustic emission (AE) signals and reveal the early-warning information during the mode I fracture process of brittle rock. The mode I fracture tests were carried out using cracked chevron notched Brazilian disc (CCNBD) specimens, which is a suggested method for determining mode I fracture toughness [35]. Real-time acoustic emission monitoring was conducted during the loading process. Variances and autocorrelation coefficients of AE count sequences with loading time were investigated through the critical slowing down theory. The average time intervals between the precursory indicator and rock fracture point for brittle rock were statistically analyzed. Finally, the critical transition characteristics of rock fracture were revealed.

\section{Critical Slowing Down Theory}

The critical transition can be characterized and predicted by the changes of some statistical parameters when a complex dynamical system undergoes sudden transition from a stable state to another contrasting one. As a concept in statistical physics, critical slowing down describes the fluctuation phenomenon when the system approaches the critical point. Specifically, critical slowing down refers to the phenomenon that the fluctuation duration is lengthened, the recovery rate decreases, and the ability to return to the previous state declines $[23,27]$. Critical slowing down phenomenon can be statistically characterized by the variance and autocorrelation coefficient.

The variance $(\delta)$ is the deviation of sample data to its mathematical expectation, expressed as follows:

$$
\delta=S^{2}=\frac{1}{N} \sum_{i=0}^{N}\left(x_{i}-E\left(x_{i}\right)\right)^{2},
$$

where $S$ and $E\left(x_{i}\right)$ represent the standard deviation and mathematical expectation, respectively, and $x_{i}$ and $N$ are the $i^{\text {th }}$ data and the number of data, respectively.

Autocorrelation coefficient statistically describes the correlation between different periods of the same variable. The autocorrelation coefficient $(\beta(k))$ of the variable $x_{i}$ with lag length $k$ can be denoted as follows:

$$
\beta(k)=\sum_{i=1}^{N-k}\left(\frac{x_{i}-E\left(x_{i}\right)}{S}\right)\left(\frac{x_{i+k}-E\left(x_{i}\right)}{S}\right) .
$$

It is assumed that the state variable has a repeated disturbance after each period $(\Delta t)$. The return to equilibrium is approximately exponential during the perturbation process with a certain recovery rate $(\alpha)$. This can be described in an autoregressive (AR) model as follows [23]:

$$
\begin{gathered}
u_{n+1}=e^{\alpha \Delta t} u_{n}+S \omega_{n}, \\
u_{n}=x_{n}-E\left(x_{n}\right),
\end{gathered}
$$

where $u_{n}$ denotes the deviation of the state variable from equilibrium and $\omega_{n}$ is a random quantity from a normal distribution.

If the recovery speed $(\alpha)$ and period $(\Delta t)$ are independent of the deviation $\left(u_{n}\right)$, this model can be simplified into an AR (1) model:

$$
u_{n+1}=\beta u_{n}+S \omega_{n} .
$$

The autocorrelation coefficient $\beta=e^{\alpha \Delta t}$ is approximately one for red noise and zero for white noise. The variance of the AR (1) model (equation (5)) is found to be

$$
\operatorname{Var}\left(u_{n+1}\right)=E\left(u_{n}^{2}\right)+\left(E\left(u_{n}\right)\right)^{2}=\frac{\delta}{1-\beta^{2}}
$$

The recovery rate of small amplitude disturbances is increasingly lower when the system approaches the critical point $[22,23]$. The variance will approximate infinity and the autocorrelation coefficient will approach 1 as the recovery rate approaches 0 . Therefore, the significant increase of variance and autocorrelation coefficient of one system parameter can be regarded as the precursor close to the critical point [30-34]. Here refers to the AE count of marble samples during the mode I fracture process.

\section{Experimental Setup}

The cracked chevron notched Brazilian disc (CCNBD) specimens are suggested for determining mode I fracture toughness by the International Society for Rock Mechanics (ISRM) [35]. The CCNBD marble specimens were prepared according to the requirements of the suggested method, as shown in Figure 1 . The radius $(R)$ and thickness $(B)$ of marble specimens are $50 \mathrm{~mm}$ and $32 \mathrm{~mm}$. The dimensions of the final chevron notched crack length $\left(a_{1}\right)$ and initial 


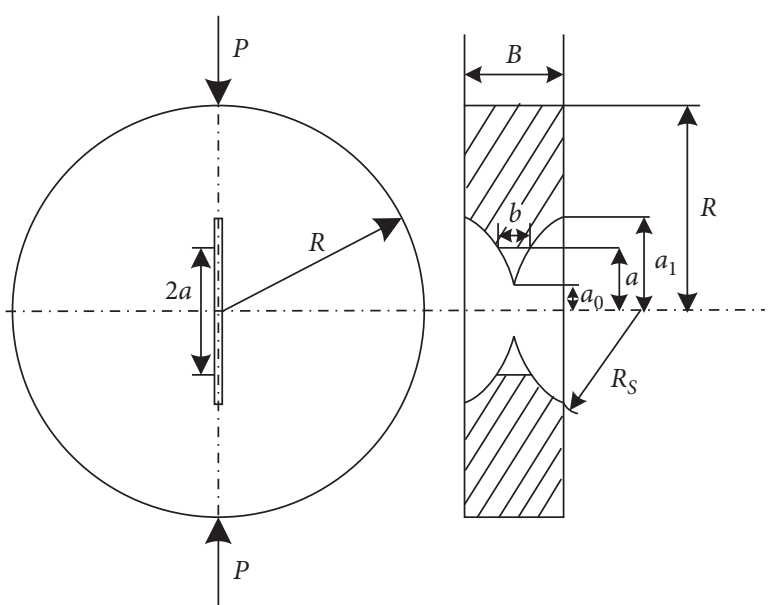

FIgURE 1: Sample geometry parameters of the CCNBD specimen (ISRM, 1995) [35].

chevron notched crack length $\left(a_{0}\right)$ are $38 \mathrm{~mm}$ and $13 \mathrm{~mm}$ on average. The density of marble specimens is $2.68 \times 10^{3} \mathrm{~kg} / \mathrm{m}^{3}$ on average. The average uniaxial compression strength (UCS) and tensile strength are 53.85 and 4.05 MPa. Mineral composition analysis showed that white marble is constituted by only a single mineral, namely, calcite. The forcecontrolled loading mode was adopted in this study. The loading rate was constant at $1 \mathrm{kN} / \mathrm{min}$. In total, there are 7 CCNBD marble specimens for mode I fracture tests.

A rock mechanics testing system (model: MTS815 Flex Test GT) with a maximum normal load of $4600 \mathrm{kN}$ was used to carry out mode I fracture tests. The force, displacement, and crack opening displacement were recorded during the tests. Force was measured by force sensors with a range of 0 to $1000 \mathrm{kN}$, while displacement and crack opening displacement were measured by linear variable differential transducers (LVDTs) with a range of $\pm 2.5 \mathrm{~mm}$ and crack opening displacement meter (COD) with a range of $-2 \mathrm{~mm}$ to $5 \mathrm{~mm}$, respectively. This configuration used in this study is according to the suggested method by ISRM [35]. An acoustic emission monitoring system (model: PCI-2), produced by American Physical Acoustics Corporation, was utilized to automatically monitor $\mathrm{AE}$ signals during the whole loading process. The experimental setup of acoustic emission monitoring is shown in Figure 2. Eight Micro30 sensors, which have a good sensitivity to AE signals, were equally distributed on the surface of each CCNBD specimen symmetrically with respect to the loading direction. Vaseline was used to guarantee good connections between $\mathrm{AE}$ sensors and rock sample. The threshold level was set as $35 \mathrm{~dB}$ in the experiments. The sampling rate was $1 \mathrm{MHz}$ and the preamplification was set as $40 \mathrm{~dB}$. The Micro30 sensor has a wide frequency response [36].

To analyze the critical slowing down feature of $\mathrm{AE}$ signals, the variances and autocorrelation coefficients of $\mathrm{AE}$ counts with loading time were calculated through a batch program written by MATLAB software.

\section{Results}

4.1. Mechanical Properties of Marble under Mode I Fracture.
Figure 3 shows the typical CCNBD sample after mode I fracture tests. According to the recommended method by ISRM, the mode I fracture toughness $\left(K_{\mathrm{IC}}\right)$ of specimen can be determined by the following equation [35]:

$$
K_{\mathrm{IC}}=\frac{P_{\max }}{B \sqrt{D}} Y_{\min }^{*}
$$

where $Y_{\min }^{*}$ refers to the critical dimensionless stress intensity for the CCNBD specimen, which is calculated by geometry dimensions of specimen only. $P_{\max }$ refers to the peak force recorded during the experiments. The symbols $B$ and $D$ are the thickness and diameter of the disc specimen, respectively.

The mode I fracture toughness of marble specimens was calculated by equation (7), as listed in Table 1 . The mode I fracture toughness is $0.636 \mathrm{MPa} \times \mathrm{m}^{1 / 2}$ on average, ranging from 0.447 to $0.797 \mathrm{MPa} \times \mathrm{m}^{1 / 2}$. The number of $\mathrm{AE}$ hits released during the rock fracture process is on average 20479 with a range of 13659 to 27321 .

According to the ISRM suggested method [35], the minimum valid diameter $\left(D_{\min }\right)$ of CCNBD specimens can be estimated as follows:

$$
D_{\min }=8.88+1.4744 \cdot\left(\frac{K_{\mathrm{IC}}}{\sigma_{t}}\right)^{-2},
$$

where $\sigma_{t}$ denotes the tensile strength of rock specimens.

The minimum valid diameter $\left(D_{\min }\right)$ for marbles in this study is approximately $68.6 \mathrm{~mm}$ calculated by equation (8). The diameter of marble specimens is $100 \mathrm{~mm}$, which is much greater than $D_{\min }$. Therefore, the mode I fracture toughness in this study is valid and accurate.

The typical force-crack opening displacement curve of the specimens is shown in Figure 4. Obviously, the crack opening displacement grows slowly with the increasing force at the initial loading stage. The crack opening displacement increases significantly after the applied force reaches the peak, while the applied force on the CCNBD specimens remains approximately constant at this stage.

\subsection{Characteristics of AE Signals Released during Mode I} Fracture Process. The typical spatial distribution of $\mathrm{AE}$ signals is presented in Figure 5. Note that black line represents the boundary of rock specimen and red lines refer to macroscopic cracks distributed in rock specimens. It can be found that the spatial distribution of AE sources agrees well with macroscopic failure pattern of rock specimens subjected to mode I fracture loading. Figure 6 shows typical acoustic emission count curve versus loading time during the mode I fracture test. Note that red dotted line in Figure 6 refers to the force-loading time curve during mode I rock fracture. On the left vertical axis is AE count while on the right vertical axis is force in $\mathrm{kN}$. There are few AE signals produced by the specimen at the initial stage. This is because the external force at this loading stage is too small to cause microcrack initiation and propagation in rocks. At this stage, $\mathrm{AE}$ signals result from the closure of preexisting cracks. Subsequently, the $\mathrm{AE}$ counts increase gradually with 


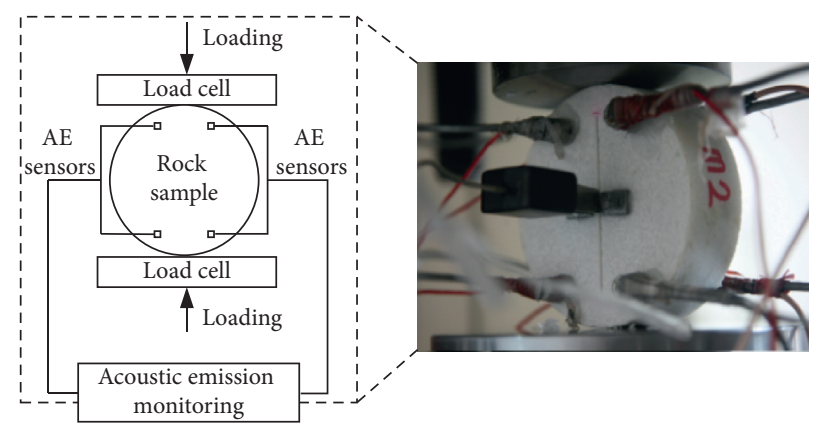

FIGURE 2: Schematic diagram of acoustic emission monitoring.

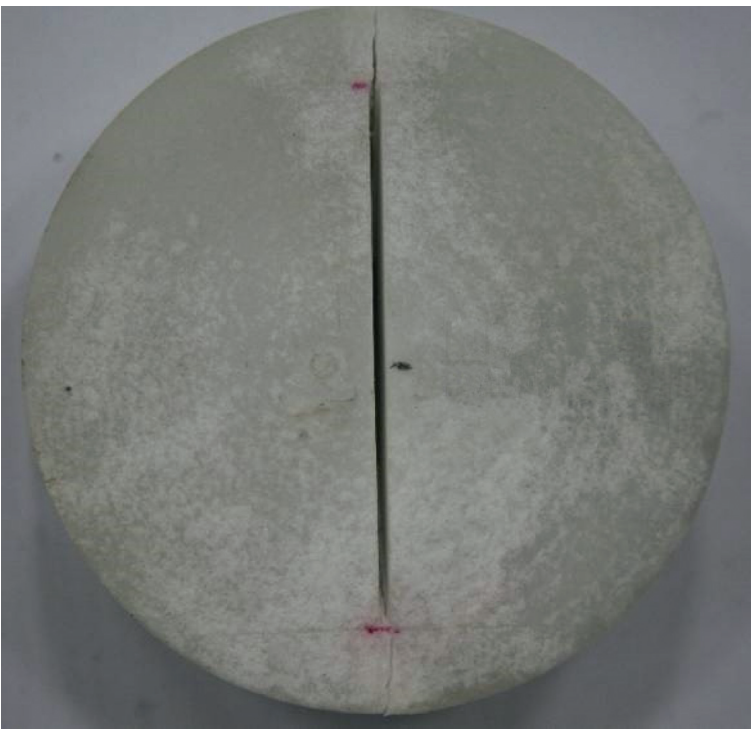

(a)

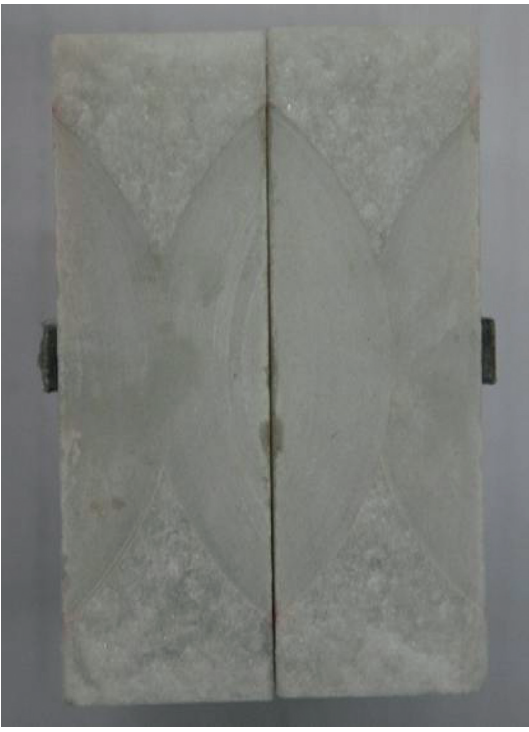

(b)

Figure 3: Typical CCNBD sample after the mode I fracture test.

TABLE 1: Fracture toughness and total AE hit of specimens.

\begin{tabular}{lcc}
\hline $\begin{array}{l}\text { Specimen } \\
\text { no. }\end{array}$ & $\begin{array}{c}\text { Mode I fracture toughness } \\
\left(\mathrm{MPa} \times \mathrm{m}^{1 / 2}\right)\end{array}$ & AE hit total \\
\hline M1 & 0.797 & 21101 \\
M2 & 0.734 & 13659 \\
M3 & 0.527 & 19071 \\
M4 & 0.783 & 25153 \\
M5 & 0.596 & 20347 \\
M6 & 0.569 & 16699 \\
M7 & 0.447 & 27321 \\
Average & 0.636 & 20479 \\
\hline
\end{tabular}

increasing force, which reflects the onset and propagation of microcracking. Significant growth of AE counts occurs as the applied force approaches the peak. Formation and penetration of macroscopic cracks occur at this stage. The release of $\mathrm{AE}$ counts is consistent with the rock fracture process.

4.3. Critical Slowing Down Feature during Mode I Fracture Process. To investigate the critical slowing down feature, appropriate window length and lag step length need to be

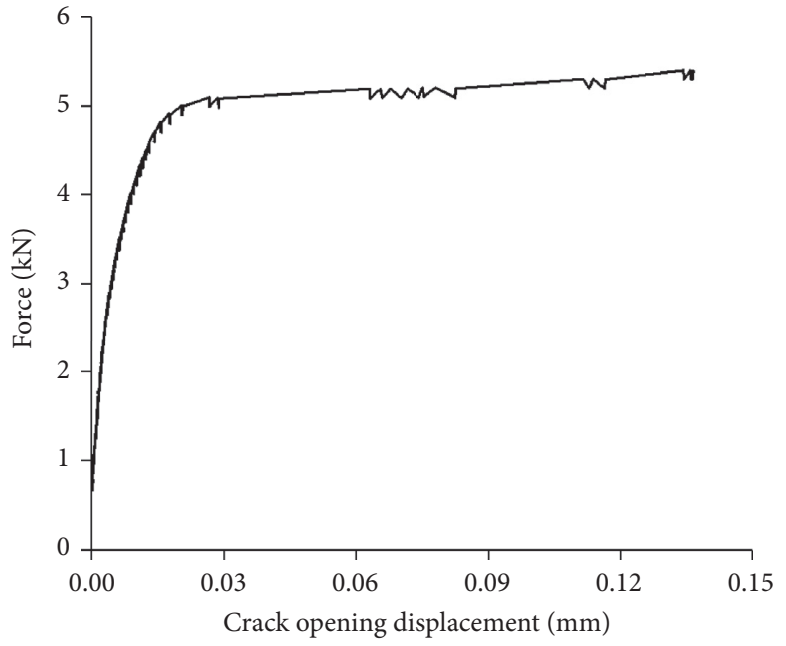

FIGURE 4: Typical force versus crack opening displacement curve of rock sample.

adopted to determine the variance and autocorrelation coefficient of AE counts. Window length is the basic unit of sequence analysis and refers to the number of data in each 


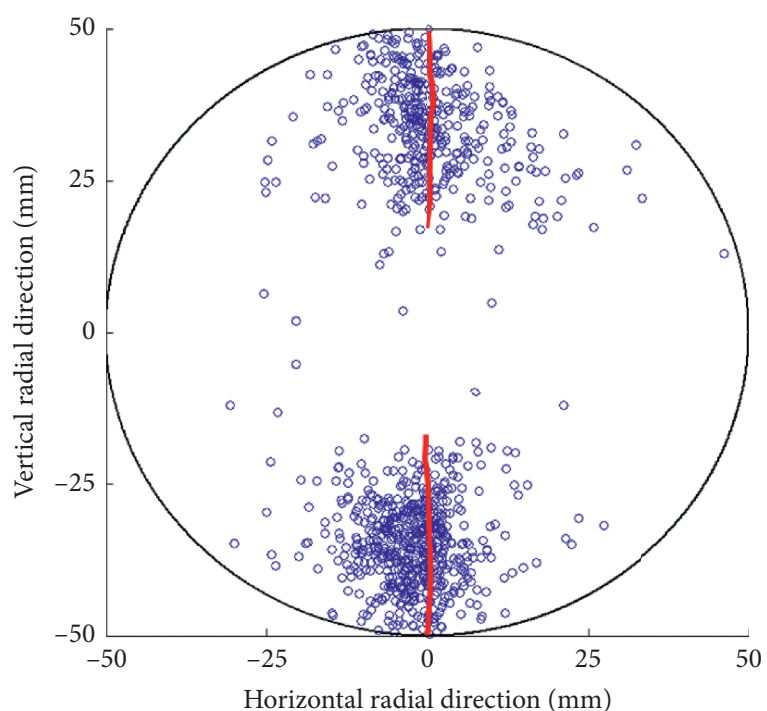

FIgURE 5: Typical spatial distribution of AE signals. Note that black line represents the boundary of rock specimen and red lines refer to macroscopic cracks distributed in rock specimens.

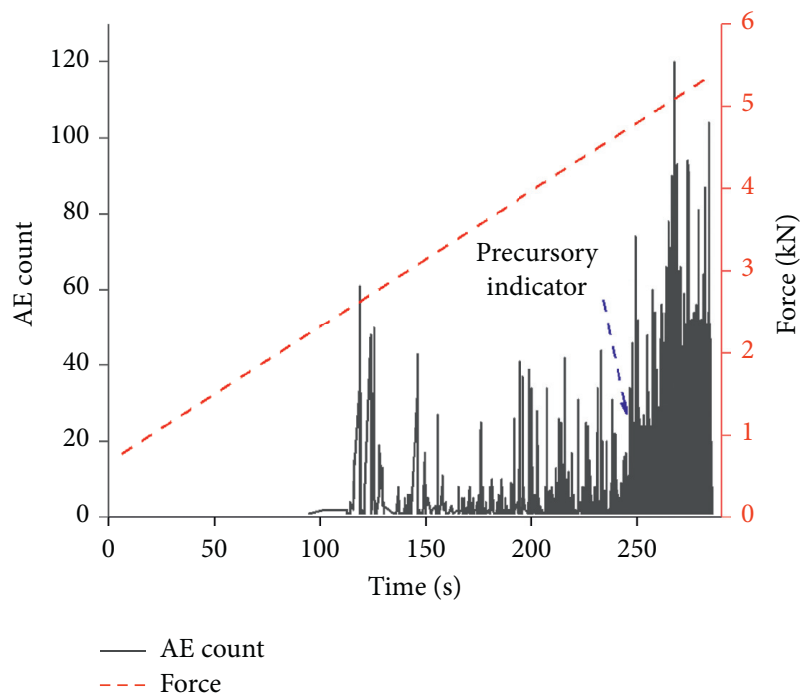

FIgUre 6: Typical AE count curve with loading time under mode I fracture.

sequence selected from the total data. The lag step length refers to the lag length from the sequence of a specific window length to another new identical sequence. Hence, the effect of different window lengths and lag step lengths on the results was analyzed. Figure 7 shows the variance and autocorrelation coefficient curves of $\mathrm{AE}$ counts under the same lag step length of 50 with different window lengths of 80,100 , and 120. For different window lengths, the overall trend of variance and autocorrelation coefficient curves is almost the same although there are differences in their magnitude. The variance and autocorrelation coefficient curves of AE counts with different lag step lengths under the same window length are presented in Figure 8. The window length was set constant at 100 , and the lag step length was set as 20,50 , and 80 , respectively. When the window length remains constant, the variance curves are consistent for different lag step lengths, while the lag step length influences autocorrelation coefficient curves. Overall, the window length and lag step length have a little effect on the results, especially the trend of variance and autocorrelation coefficient curves. The window length of 100 with a lag step length of 50 was adopted in the following analysis.

Figure 9 shows the variance and autocorrelation coefficient curves of AE counts with loading time. Obviously, there are sudden and significant increases in the variance and autocorrelation coefficient curves preceding rock fracture. This indicates the critical slowing down phenomenon exists during the rock fracture process. By comparing Figures 9(a) and 9(b), the precursory indicator is easier to identify in the variance curve compared to the autocorrelation coefficient curve. The critical slowing down feature characterized by variances is more remarkable than autocorrelation coefficients. This is due to differences between the mathematical meaning and range of the two parameters. The variance is the deviation of sample data to its mathematical expectation, while autocorrelation coefficient statistically describes the correlation between different periods of the same variable. The variance can be a very large value, whereas the range of autocorrelation coefficient is from -1 to 1. Thus, the change of variance is more remarkable compared to autocorrelation coefficient. According to the critical slowing down feature of $\mathrm{AE}$ counts, the sudden and significant growth of variance and autocorrelation coefficient, especially variance, can be viewed as the precursory indicator for imminent rock fracture. The precursory indicator is automatically identified by the magnitude and gradient of changes.

Time intervals between the precursory indicator and failure moment for different specimens are shown in Figure 10. The time intervals between the precursory indicator and failure moment range from 3.36 to 42.94 seconds with an average of 13.68 seconds.

To study the relationship between the precursory indicator and the loading process, ratios of precursory indicator to failure moment in time and force are shown in Table 2. The average ratios of the precursory indicator to failure moment in time and load are $95.69 \%$ and $95.62 \%$, respectively. The ratios of the precursory indicator to failure moment range from approximately $85 \%$ to $98 \%$ in terms of both time and force. In other words, the period between precursory signal and fracture time of marble specimens occupies $2 \%-15 \%$ of the fracture time after analysis of critical slowing down feature. Therefore, the critical slowing down theory has great potential for predicting rock fracture.

\section{Discussion}

According to analysis results, the phenomenon of critical slowing down exists during the mode I rock fracture process, which is a new method to identify whether a rock is approaching fracture. This further verifies that the critical slowing down feature is ubiquitous for complex dynamical systems in nature, spanning from ecosystems to seismic systems $[27,29,30]$. The time intervals between the 


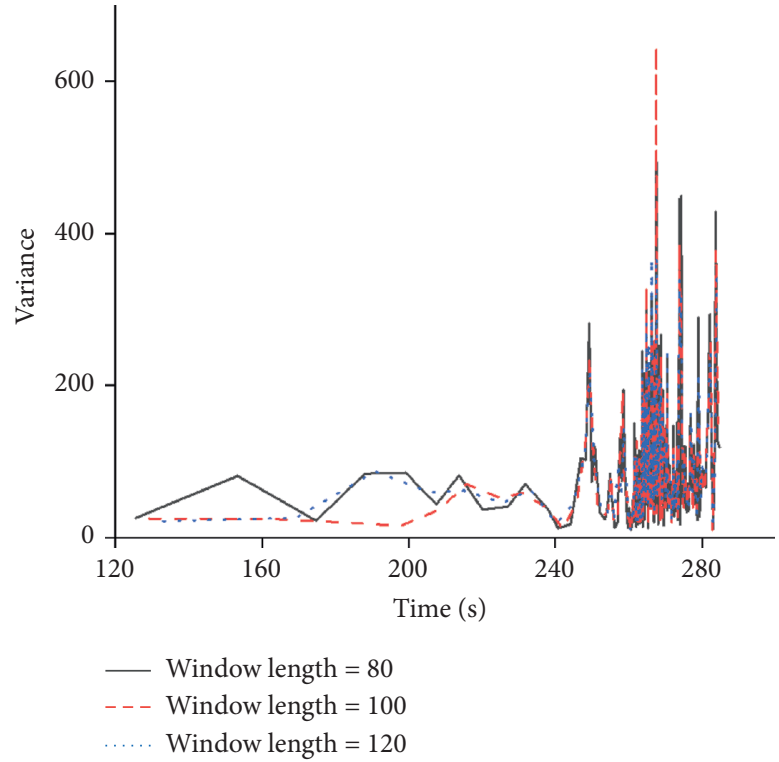

(a)

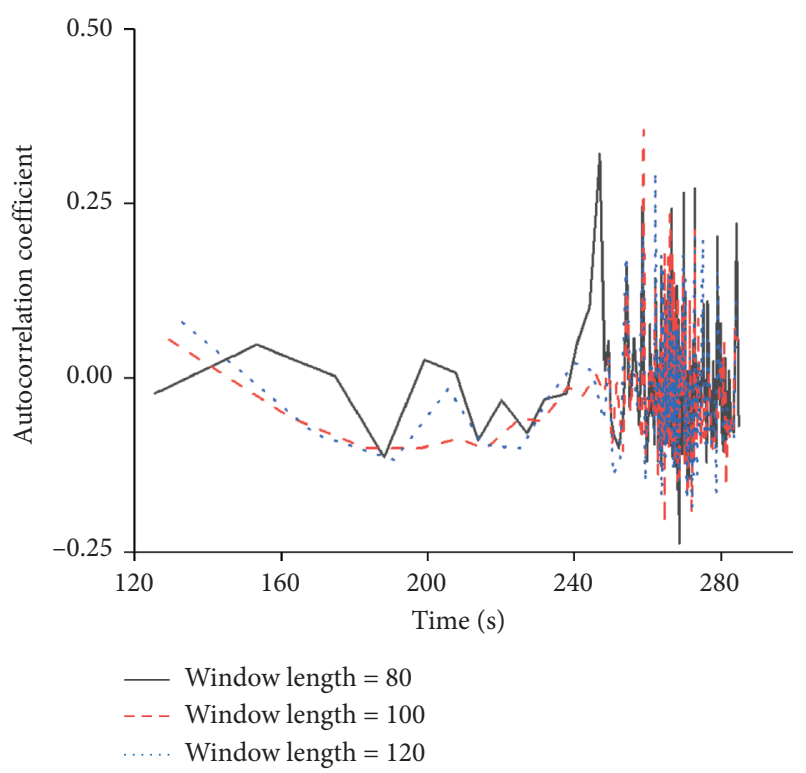

(b)

Figure 7: Variance and autocorrelation coefficient curves of AE counts with different window lengths under the same lag step length: (a) variance; (b) autocorrelation coefficient.

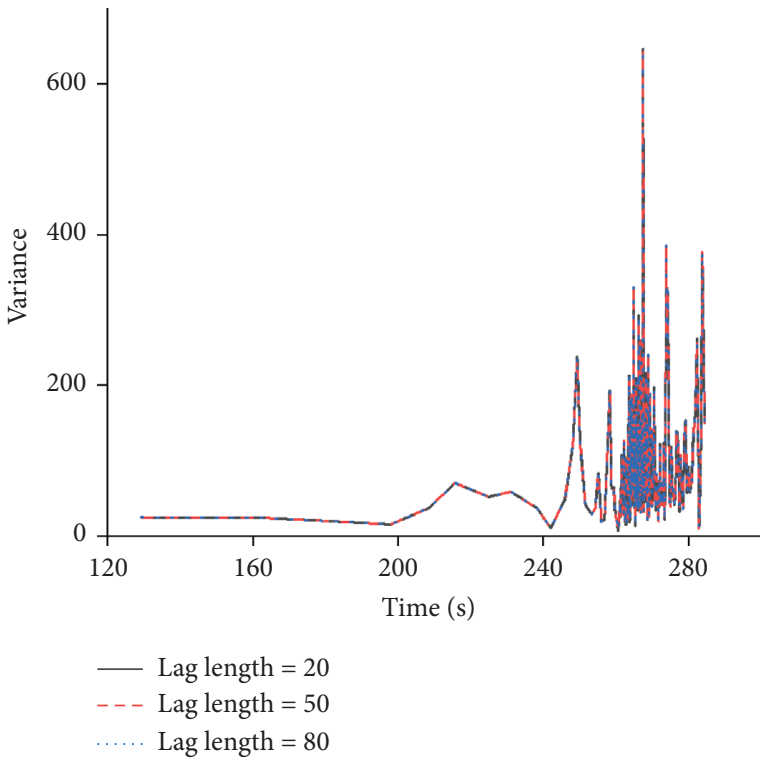

(a)

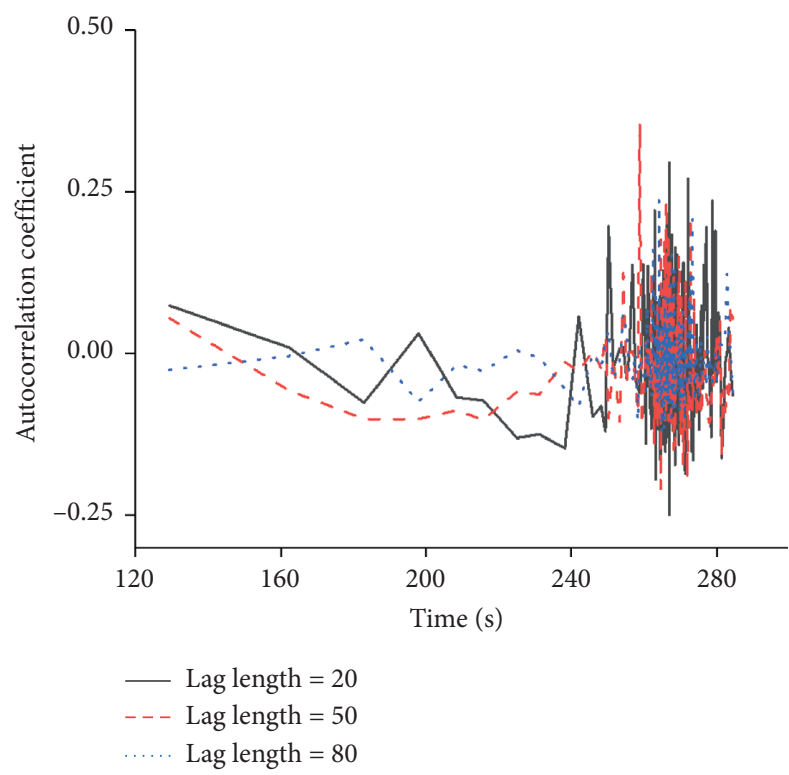

(b)

Figure 8: Variance and autocorrelation coefficient curves of AE counts with different lag step lengths under the same window length: (a) variance; (b) autocorrelation coefficient.

precursory indicator using critical slowing down theory and fracture moment (averagely $4 \%$ with a range of $2 \%-15 \%$ ) are not very short or long compared to total loading time. This is of great significance for early-warning sudden fracture of rock because it is meaningless if the early-warning time is too short or too long. The findings in this study could facilitate better understandings on the rock fracture process and early-warning technique of rock fracture-related geological disasters.
As shown in Section 4.3, the range of time intervals between the precursory indicator and failure moment is from 3.36 to 42.94 seconds, and the period between precursory signal and fracture time of marble specimens occupies $2 \%-15 \%$ of the loading time. It can be found that there are differences between the results of different marble specimens. The differences may be attributed to the discrepancy between microstructure of specimens although white marble is constituted by only calcite. The spatial 


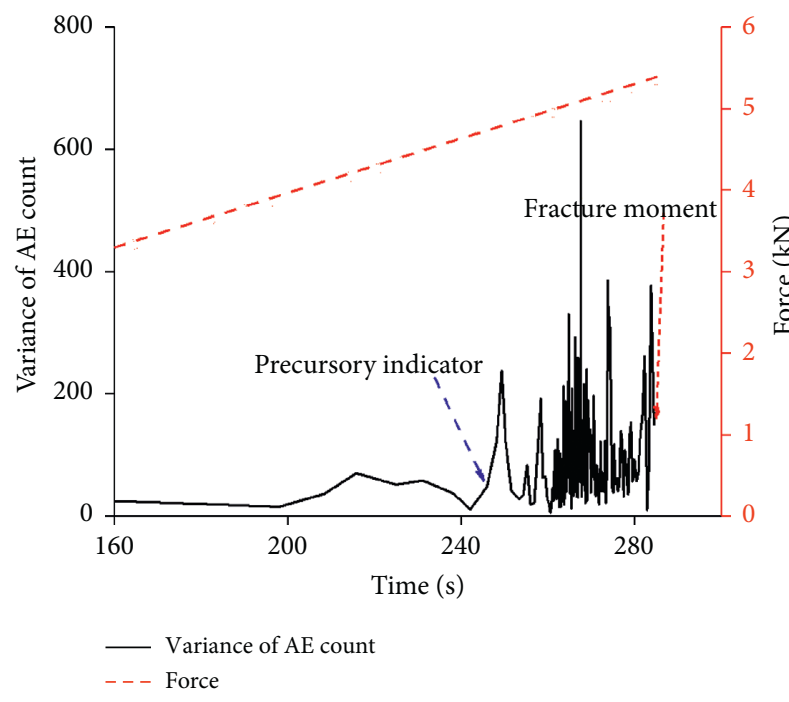

(a)

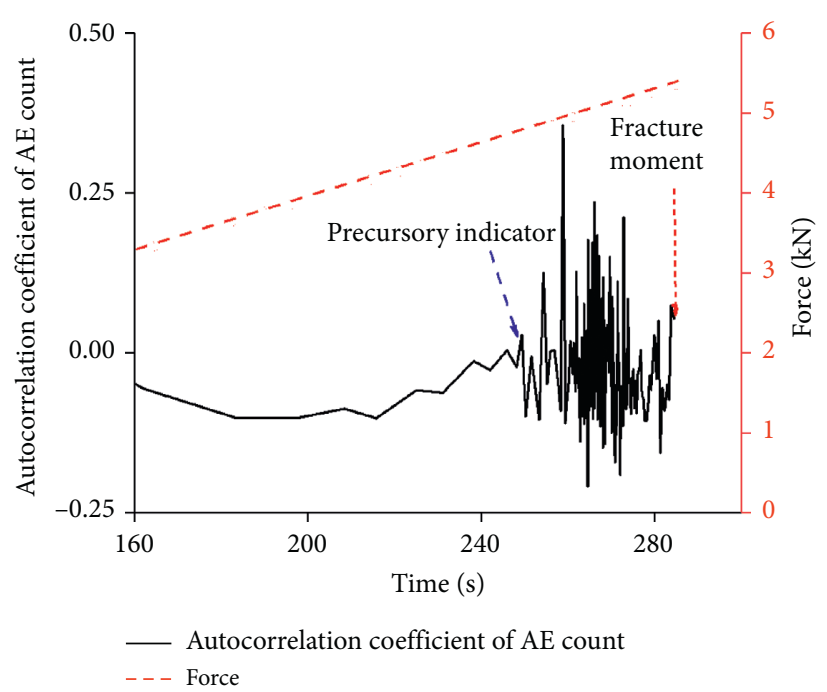

(b)

FIGURE 9: Variance and autocorrelation coefficient curves of AE counts with the loading time: (a) variance; (b) autocorrelation coefficient.

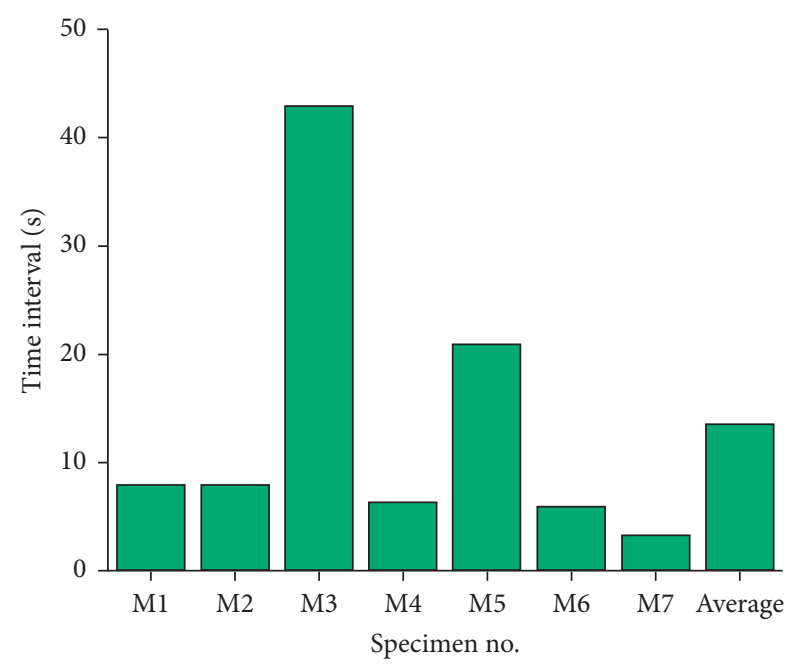

FIGURE 10: Time intervals between the precursory indicator and failure moment.

TABLE 2: Ratios of the precursory indicator to failure moment in time and force.

\begin{tabular}{|c|c|c|}
\hline \multirow[t]{2}{*}{ Specimen no. } & \multicolumn{2}{|c|}{$\begin{array}{l}\text { Ratio of the precursory } \\
\text { indicator to failure moment } \\
(\%)\end{array}$} \\
\hline & Time & Force \\
\hline M1 & 98.21 & 98.00 \\
\hline M2 & 97.87 & 97.46 \\
\hline M3 & 85.13 & 86.14 \\
\hline M4 & 98.49 & 98.19 \\
\hline M5 & 93.45 & 93.74 \\
\hline M6 & 98.12 & 97.86 \\
\hline M7 & 98.59 & 97.98 \\
\hline Average & 95.69 & 95.62 \\
\hline
\end{tabular}

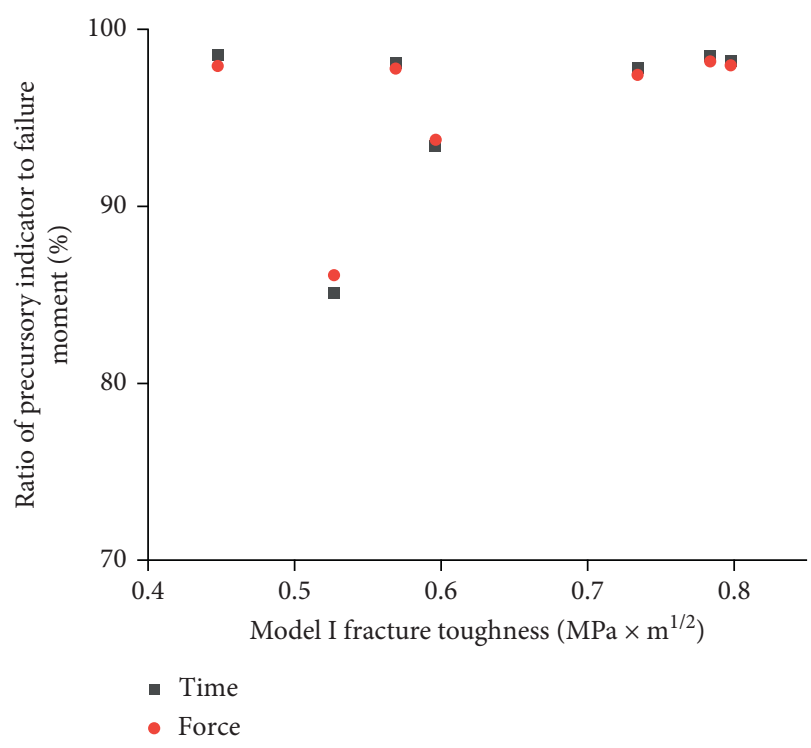

FIgURE 11: Scatter diagram between the ratios of the precursory indicator to failure moment and mode I fracture toughness of marble specimens.

distribution and quantity of preexisting defects, e.g., preexisting microcracks, pores, and cleavage, affect the rock fracture process subjected to external load.

A comparison was made between the precursory point obtained by the AE count curve directly and that of variance and autocorrelation coefficient, as shown in Figures 6 and 9. It is found that the precursory indicator through the variance and autocorrelation coefficient of $\mathrm{AE}$ counts approximates that obtained by the AE count curve directly. However, compared to the direct determination of the precursory indicator through $\mathrm{AE}$ response, i.e., the remarkable growth in $\mathrm{AE}$ counts $[8,9]$, the precursory indicator through critical 
slowing down analysis is more precise and recognizable. Furthermore, compared to seismic $b$-value, which is also applied to analyze the rock failure process [10-12], the change of the variance and autocorrelation coefficient preceding rock fracture is easier to identify. This advantage is crucial for engineers.

To discuss whether there is a certain relationship between the ratio of the precursory indicator to failure moment and mode I fracture toughness, a comparison was made among different marble specimens. Scatter diagram between the ratios of the precursory indicator to failure moment and mode I fracture toughness of marble specimens is shown in Figure 11. The ratios of the precursory indicator to failure moment in terms of time and force are relatively stable when the mode I fracture toughness of rock specimens varies.

Acoustic emission response can reflect the influence of preexisting defects on the rock failure process indirectly. However, direct measurement of preexisting defects through three-dimensional CT scanning or other methods would be much more convincing. Further study on the effect of preexisting defects on the critical slowing down characteristics is needed. Furthermore, the present study investigated the precursory information for mode I fracture of rock based on the critical slowing down theory. Further study on mode II and mixed-mode loading conditions is needed.

\section{Conclusions}

The study investigated the precursory indicator of AE signals during mode I rock fracture through critical slowing down analysis. The following conclusions are drawn:

(1) The critical slowing down phenomenon exists during mode I rock fracture. The variance and autocorrelation coefficient of AE count sequences grow significantly preceding rock fracture.

(2) The significant growth of variance and autocorrelation coefficient of $\mathrm{AE}$ signals can be viewed as the precursory indicator of rock fracture. Compared to autocorrelation coefficient, the precursors determined by variance are more remarkable.

(3) The time interval between the precursory indicator using critical slowing down theory and fracture moment ranges from $2 \%$ to $15 \%$ of the loading time.

(4) The difference between different specimens may be attributed to the discrepancy between microstructure of specimens, especially the spatial distribution and quantity of preexisting defects.

\section{Data Availability}

The data used to support the findings of this study are available from the corresponding author upon request.

\section{Conflicts of Interest}

The authors declare that they have no conflicts of interest.

\section{Acknowledgments}

This study was financially supported by the National Natural Science Foundation of China (nos. 51909026, 51974055, 51774064, and 41941018), the Fundamental Research Funds for the Central Universities (Grant no. DUT20GJ216), and the National Key Research and Development Program of China (no. 2018YFC1505301).

\section{References}

[1] M. Ohtsu, "Simplified moment tensor analysis and unified decomposition of acoustic emission source: application to in situ hydrofracturing test," Journal of Geophysical Research: Solid Earth, vol. 96, no. B4, pp. 6211-6221, 1991.

[2] Z.-H. Zhang, J.-H. Deng, J.-B. Zhu, and L.-R. Li, "An experimental investigation of the failure mechanisms of jointed and intact marble under compression based on quantitative analysis of acoustic emission waveforms," Rock Mechanics and Rock Engineering, vol. 51, no. 7, pp. 2299-2307, 2018.

[3] D. G. Aggelis, "Classification of cracking mode in concrete by acoustic emission parameters," Mechanics Research Communications, vol. 38, no. 3, pp. 153-157, 2011.

[4] J. Karser, A Study of Acoustic Emission Phenomena in Tensile Tests, Technische Hochschule Munchen, Munich, Germany, 1950.

[5] M. Ohnaka and K. Mogi, "Frequency characteristics of acoustic emission in rocks under uniaxial compression and its relation to the fracturing process to failure," Journal of Geophysical Research, vol. 87, no. B5, pp. 3873-3884, 1982.

[6] R. Prikryl, T. Lokajíček, C. Li, and V. Rudajev, "Acoustic emission characteristics and failure of uniaxially stressed granitic rocks: the effect of rock fabric," Rock Mechanics and Rock Engineering, vol. 36, no. 4, pp. 255-270, 2003.

[7] K.-H. Li, P. Cao, K. Zhang, and Y.-F. Zhong, "Macro and meso characteristics evolution on shear behavior of rock joints," Journal of Central South University, vol. 22, no. 8, pp. 3087-3096, 2015.

[8] T. Shiotani, M. Ohtsu, and K. Ikeda, "Detection and evaluation of AE waves due to rock deformation," Construction and Building Materials, vol. 15, no. 5-6, pp. 235-246, 2001.

[9] M. Cai, H. Morioka, P. K. Kaiser et al., "Back-analysis of rock mass strength parameters using AE monitoring data," International Journal of Rock Mechanics and Mining Sciences, vol. 44, no. 4, pp. 538-549, 2007.

[10] C. H. Scholtz, "The frequency-magnitude relation of microfracturing in rock and its relation to earthquakes," Bulletin of the Seismological Society of America, vol. 58, no. 1, pp. 399415, 1968.

[11] X. Lei, K. Masuda, O. Nishizawa et al., "Detailed analysis of acoustic emission activity during catastrophic fracture of faults in rock," Journal of Structural Geology, vol. 26, no. 2, pp. 247-258, 2004.

[12] Z. Zhang, R. Zhang, H. Xie, J. Liu, and P. Were, "Differences in the acoustic emission characteristics of rock salt compared with granite and marble during the damage evolution process," Environmental Earth Sciences, vol. 73, no. 11, pp. 6987-6999, 2015.

[13] Y. H. Li, J. P. Liu, X. D. Zhao, and Y. J. Yang, "Experimental studies of the change of spatial correlation length of acoustic emission events during rock fracture process," International Journal of Rock Mechanics and Mining Sciences, vol. 47, no. 8, pp. 1254-1262, 2010. 
[14] Z. Zhang, E. Wang, N. Li, X. Li, X. Wang, and Z. Li, "Damage evolution analysis of coal samples under cyclic loading based on single-link cluster method," Journal of Applied Geophysics, vol. 152, pp. 56-64, 2018.

[15] M. C. He, J. L. Miao, and J. L. Feng, "Rock burst process of limestone and its acoustic emission characteristics under truetriaxial unloading conditions," International Journal of Rock Mechanics and Mining Sciences, vol. 47, no. 2, pp. 286-298, 2010.

[16] L. R. Li, J. H. Deng, L. Zheng, and J. F. Liu, "Dominant frequency characteristics of acoustic emissions in white marble during direct tensile tests," Rock Mechanics and Rock Engineering, vol. 50, no. 5, pp. 1337-1346, 2017.

[17] T. Hirata, T. Satoh, and K. Ito, "Fractal structure of spatial distribution of microfracturing in rock," Geophysical Journal International, vol. 90, no. 2, pp. 369-374, 1987.

[18] H. P. Xie, J. F. Liu, Y. Ju, J. Li, and L. Z. Xie, "Fractal property of spatial distribution of acoustic emissions during the failure process of bedded rock salt," International Journal of Rock Mechanics and Mining Sciences, vol. 48, no. 8, pp. 1344-1351, 2011.

[19] R. Zhang, F. Dai, M. Z. Gao, N. W. Xu, and C. P. Zhang, "Fractal analysis of acoustic emission during uniaxial and triaxial loading of rock," International Journal of Rock Mechanics and Mining Sciences, vol. 79, pp. 241-249, 2015.

[20] X. Kong, E. Wang, X. He, D. Li, and Q. Liu, “Time-varying multifractal of acoustic emission about coal samples subjected to uniaxial compression," Chaos, Solitons \& Fractals, vol. 103, pp. 571-577, 2017.

[21] S. W. Zhang, K. J. Shou, X. F. Xian, J. P. Zhou, and G. J. Liu, "Fractal characteristics and acoustic emission of anisotropic shale in Brazilian tests," Tunnelling and Underground Space Technology, vol. 71, pp. 298-308, 2018.

[22] V. Dakos, M. Scheffer, E. H. Van Nes, V. Brovkin, V. Petoukhov, and H. Held, "Slowing down as an early warning signal for abrupt climate change," Proceedings of the National Academy of Sciences, vol. 105, no. 38, pp. 1430814312, 2008.

[23] M. Scheffer, J. Bascompte, W. A. Brock et al., "Early-warning signals for critical transitions," Nature, vol. 461, no. 7260, pp. 53-59, 2009.

[24] V. Dakos and J. Bascompte, "Critical slowing down as early warning for the onset of collapse in mutualistic communities," Proceedings of the National Academy of Sciences, vol. 111, no. 49, pp. 17546-17551, 2014.

[25] E. A. Gopalakrishnan, Y. Sharma, T. John, P. S. Dutta, and R. I. Sujith, "Early warning signals for critical transitions in a thermoacoustic system," Nature, vol. 6, pp. 1-10, 2016.

[26] H. Wu, W. Hou, and P. C. Yan, "Using the principle of critical slowing down to discuss the abrupt climate change," Acta Physica Sinica, vol. 62, no. 3, pp. 1-10, 2013, in Chinese.

[27] E. H. Van Nes and M. Scheffer, "Slow recovery from perturbations as a generic indicator of a nearby catastrophic shift," The American Naturalist, vol. 169, no. 6, pp. 738-747, 2007.

[28] R. A. Chisholm and E. Filotas, "Critical slowing down as an indicator of transitions in two-species models," Journal of Theoretical Biology, vol. 257, no. 1, pp. 142-149, 2009.

[29] K. K. Beck, M.-S. Fletcher, P. S. Gadd et al., "Variance and rate-of-change as early warning signals for a critical transition in an aquatic ecosystem state: a test case from Tasmania, Australia," Journal of Geophysical Research: Biogeosciences, vol. 123, no. 2, pp. 495-508, 2018.
[30] R. Yan, C. Jiang, and L. Zhang, "Study on critical slowing down phenomenon of radon concentrations in water before the Wenchuan MS8.0 earthquake," Chinese Journal of Geophysics, vol. 54, no. 7, pp. 1817-1826, 2011, in Chinese.

[31] H. Ren and D. Watts, "Early warning signals for critical transitions in power systems," Electric Power Systems Research, vol. 124, pp. 173-180, 2015.

[32] X. Kong, E. Wang, S. Hu et al., "Critical slowing down on acoustic emission characteristics of coal containing methane," Journal of Natural Gas Science and Engineering, vol. 24, pp. 156-165, 2015.

[33] Y. Wei, Z. Li, X. Kong et al., "The precursory information of acoustic emission during sandstone loading based on critical slowing down theory," Journal of Geophysics and Engineering, vol. 15, no. 5, pp. 2150-2158, 2018.

[34] X. Zhang, Z. Li, Y. Niu, F. Cheng, M. Ali, and S. Bacha, "An experimental study on the precursory characteristics of EP before sandstone failure based on critical slowing down," Journal of Applied Geophysics, vol. 170, pp. 1-10, 2019.

[35] ISRM Testing Commission and R. J. Fowell, "Suggested method for determining mode I fracture toughness using cracked chevron notched Brazilian disc (CCNBD) specimens," International Journal of Rock Mechanics and Mining Sciences \& Geomechanics Abstracts, vol. 32, pp. 57-64, 1995.

[36] Z. H. Zhang and J. H. Deng, "A new method for determining the crack classification criterion in acoustic emission parameter analysis," International Journal of Rock Mechanics and Mining Sciences, vol. 130, Article ID 104323, 2020. 